\title{
Activating CD79B Gene Mutation
}

National Cancer Institute

\section{Source}

National Cancer Institute. Activating CD79B Gene Mutation. NCI Thesaurus. Code C150435.

A change in the nucleotide sequence of the CD79B gene that that results in constitutive activation of B-cell antigen receptor complex-associated protein beta chain and its downstream signaling pathways. 